\title{
Prevalence and associated risk factors of intestinal parasitic infections among primary school children at Bure town, north-west Ethiopia
}

\author{
Baye Sitotaw $^{1, *}$, Yezina Gebeyaw ${ }^{2}$ and Haile Mekonnen ${ }^{3}$ \\ ${ }^{1}$ Bahir Dar University, Department of Biology, Ethiopia \\ ${ }^{2}$ ANRS, Bure Town Education Office, Amhara Region, Ethiopia \\ ${ }^{3}$ Bahir Dar University, Department of Statistics, Ethiopia
}

\begin{abstract}
The burden of intestinal parasitic infections (IPIs) has been a common problem on children in Ethiopia. While communities in Bure town, northwest Ethiopia, are presumed to be exposed to IPIs, no study has been conducted before. The aim of this study was therefore to assess the prevalence of IPIs and associated risk factors among school children in Bure town by conducting a cross-sectional study from January to June 2019. A total of 430 students were selected using stratified systematic random sampling technique. Direct wet-mount and formal-ether concentration techniques were used for parasitological analysis from stool samples taken from each student. Information about the risk factors was collected using structured questionnaire. Data were analyzed using SPSS version 24. The overall prevalence of IPIs among the children involved in the study was found to be $40 \%(172 / 430)$. Some $37.7 \%$ of the students exhibited single parasite infection, $2.1 \%$ double and $0.23 \%$ triple parasite. Seven species of intestinal parasites were detected, and Entamoeba histolytica/dispar was the most prevalent parasite $(22.1 \%)$ followed by Giardia lamblia (8.6\%), hookworms $(6.75 \%)$ and Ascaris lumbricoides (3.7\%). Hymenolepis nana, Trichuris trichuira and Taenia species were rare $(<1 \%$ prevalence each). Knowledge about personal and food hygiene as well as environmental sanitation were the most important predictors for IPIs $(P<0.05)$. Primary school children in Bure town are at high risk of IPIs. Awareness creation on personal hygiene and environmental sanitation is strongly recommended.
\end{abstract}

Keywords: Intestinal parasitic infections, Prevalence, Primary school children, Risk factor, Bure town

DOI: https://dx.doi.org/10.4314/ejst.v13i2.4

"Corresponding author: mershabaye@gmail.com

(C) This is an Open Access article distributed under the terms of the Creative Commons Attribution License (http://creativecommons.org/licenses/CC BY4.0) 


\section{INTRODUCTION}

Intestinal parasitosis caused by one or more species of protozoa, cestodes, trematodes and nematodes has been a public health burden globally (Ojha et al., 2014). Several of such infectious diseases have already been identified as Neglected Tropical Diseases (NTDs) (Collier, 2007; Hotez et al., 2009; WHO, 2010; Hotez et al., 2014), and they have recently received attention. Accordingly, eradication of NTD through the control of the transmission of IPIs and the mitigation of possible risk factors is one of the sustainable development goals of the United Nations (2030 Agenda; Goal 3.3). As a result, diagnosis of these parasitic diseases has improved a lot. Despite these efforts, most parasitic diseases continue to pose major public health problems, particularly in tropical and subtropical regions (Collier, 2007; Hotez et al., 2009; Hotez et al., 2014).

The high prevalence of IPIs in developing countries depends on several factors (Alum et al., 2010). Poverty linked factors such as poor sanitation, scarcity of potable water, unsafe human waste disposal systems, open field defecation, the prevailing bad climate, and local environmental conditions are the most important risk factors identified. In addition, insufficient health services, as well as lack of the required awareness, due probably to the absence of effective health education are among the contributing factors for the elevated IPIs among poor communities (Sady et al., 2015; Alganesh Gebreyohanis et al., 2018; Palmeirim et al., 2018).

Many studies elsewhere indicated that young children were disproportionately affected by IPIs compared to adults due to a less developed immune system, poor personal hygiene and the habit of playing on contaminated soil. IPIs could result in reduced growth, increased risk of protein-energy malnutrition, iron deficiency anemia and reduced cognitive/psychomotor development in young children (Sackev, 2001; WHO, 2010). Millions of pre-school and school children are living in areas where the intestinal parasites are widely transmitted and in need of urgent treatment and preventive interventions (WHO, 2010).

Globally, IPIs caused by pathogenic protozoan species have been reported to be high. Amoebiasis caused by E. histolytica is one of the severe diseases, infecting 48 million individuals. The global prevalence of giardiasis is also high (WHO, 2010). Moreover, parasitic worms such as roundworm (Ascaris), hookworm and whipworm remain a global burden in low-income countries (Hotez et al., 2009; WHO, 2010; Mascarini-Serra, 2011; Hotez et al., 2014). The protozoan parasite and the soil-transmitted helminths are thus the most prevalent intestinal parasites, resulting in high morbidity and mortality particularly in developing nations such as in sub-Saharan African countries (WHO, 2010). Many reports 
have shown that the frequency of IPIs in the region is extremely high, affecting nearly all inhabitants at some point during their lives.

Federal Ministry of Health of Ethiopia (FMHE) launched the Health Extension Program (HEP) in 2003, made operational since 2004, by training thousands of Health Extension Workers (HEW) and assigning them in villages. The HEWs focus on disease prevention and health promotion at the village level, which is the health policy of the Ethiopian government since the turn of the $21^{\text {st }}$ century. The program was meant to accelerate the country's progress in meeting some of the Millennium Development Goals (MDGs). Despite the efforts, a significant segment of the Ethiopian population is still under high burden of IPIs due to the risk factors linked to poverty and lack of awareness on ways of disease prevention and control (Ashenafi Abosie and Mohammed Seid, 2014; Alganesh Gebreyohannis et al., 2018). Thus, in the different regions of Ethiopia, elevated prevalence of IPIs (up to 84\%) was reported among high-risk groups such as primary school children (Ashenafi Abosie and Mohammed Seid, 2014; Merem Abdi et al., 2015; Tamirat Hailegebrael, 2017; Baye Sitotaw et al., 2019).

According to reports from clinics and health centers in Bure town, many people visit health centers mainly due to IPIs. However, there was no previous study conducted on the prevalence of IPIs and associated risk factors in Bure town. Therefore, this study was conducted to estimate the prevalence of IPIs and associated risk factors among primary school children in Bure town.

\section{MATERIALS AND METHODS}

\section{Study design and study area}

A school based cross-sectional parasitological study was conducted from January to June 2019 to determine the prevalence of IPIs and associated risk factors among students of Bure primary schools, north-west Ethiopia. Bure town is located $410 \mathrm{~km}$ north-west of Addis Ababa (the capital city of Ethiopia). Bure town is the capital of Bure district and is located at the geographical location of $10^{\circ} 42^{\prime} \mathrm{N}$ and $37^{\circ} 04^{\prime} \mathrm{E}$ and an elevation of about 2091 meters above sea level. Agro-ecologically, most parts of the area around the town (about $82 \%$ ) is intermediate altitude. The annual mean temperature of the town is about $22{ }^{\circ} \mathrm{C}$, and the average annual rainfall ranges from 1400 to $2200 \mathrm{~mm}$. Based on the 2015 national housing and population census, the total population of Bure town was 76,368 , of whom 37,820 were male and 38,548 were female. The main source of income for the population in the area is agriculture and trade. The area is one of the consistently surplus producer districts of the region. Relatively, the 
district has better road density, connected by all-weather roads to the neighboring districts and regions, that improved market access for agricultural inputs and farm products to different regions.

In Bure town administration, there are two hospitals (one government owned, one private), one health center, two private clinics and eight health posts that provide routine health services for the population of the town. In 2018/19, five thousand students were enrolled in the 6 general primary schools (1-8) and 5 first cycle primary schools (1-4). According to secondary data obtained from Bure town health office and water service management office, the health coverage in the town was $97 \%$, while water coverage was $57 \%$ in the rural area and $63 \%$ in the town. Water supply and latrines were available for the students in the four selected schools. According to the information obtained from Bure town health office, mass de-worming campaign was practiced in the area once a year with full coverage of school children. Mass de-worming was conducted at the end of June (2019), right after we completed our sampling.

\section{Study population, sample size and sampling procedures}

The study population was all school children enrolled in Bure general primary Schools (from grades 1 to 8 ). The total number of enrolled students in the 2018/19 academic year was 5820. Since there was no similar study previously conducted in the area, a $50 \%$ prevalence rate of IPIs was taken, assuming that IPI is significantly prevalent among Bure primary school children. Accordingly, the minimum number of sample size (n) required was determined using single population proportion formula for cross-sectional surveys (Naing et al., 2006), i.e., $\mathrm{n}=\mathrm{Z}^{2} \mathrm{p}(1-\mathrm{p}) / \mathrm{d}^{2}=1.96^{2 *} 0.50 * 0.50 / .05^{2}=384$ students. To compensate for the non-respondents and to minimize errors probably arising from the likelihood of non-compliance, $12 \%$ of the calculated sample size was added giving a final sample size of 430 study participants. Four primary schools were purposely selected (two from rural and two from urban) for this study. Study participants were then selected using systematic random sampling from the students stratified into grade levels (Grades 1 to 8 ) according to the standards in Williams et al. (2012) to include 430 school children.

\section{Sample collection and processing}

A structured questionnaire based on known risk factors was developed in English and translated into Amharic (local language). The participants of the study (parents in the case of younger children) were interviewed to obtain sociodemographic data, hygienic practices and knowledge of the participants about personal hygiene, food hygiene, and environmental sanitation. For the assessment of the level of knowledge, participants were asked whether the 
following factors could be means of intestinal parasitic infections or not: untrimmed fingernails and dirty fingernails, not washing hands after toilet use, not washing hands before and after a meal, eating uncooked meat and or unwashed fruits and vegetables, drinking water from unprotected sources (streams, rivers or unprotected springs) without treating (boiling or adding chemical), disposing of wastes, as well as defecating in the open field. Those participants who said "no" for more than $75 \%$ of the questions were rated as having poor knowledge while those who replied "yes" for more than $75 \%$ of the questions were rated as having good knowledge. Then, the responses were translated back into English. The questionnaire was pre-tested using forty individuals outside the study area in a non-study sample population.

For parasitological analysis, fresh stool samples were collected. The children were instructed properly and given clean labeled collection cups along with applicator sticks, and from each student, about $2 \mathrm{~g}$ of fresh stool was collected. At the time of collection, date of sampling, the name of the participant, age and sex were recorded for each subject in a recording format. Stool sample was transported to Bure Health Center Laboratory. A portion of each of the stool samples was processed and examined microscopically using direct wet-mount, while the other portion was processed and examined using formal-ether concentration techniques following the procedures in the WHO guidelines (WHO, 2000). All developmental stages of the parasites, i.e., cysts, eggs, larvae and adults were recorded.

\section{Data analysis}

Statistical Package for Social Science (SPSS) software version 24 was used to analyze the data. Chi-square $\left(\chi^{2}\right)$ test was performed to verify the possible association between the prevalence of IPIs and socio-demographic characteristics, behavioral factors, hygienic practices, and environmental sanitation factors. Logistic regression was used to measure the strengths of the association between the infection and the risk factors using odds ratio. In the modeling process, a bivariate analysis was first done with a 0.25 level of significance to select the candidate variables for multivariate analysis. The variables, significant in the bivariate analysis were then included in the multivariate analysis (Lemeshow et al., 2013). Values were considered statistically significant at $P<0.05$.

\section{Limitation of the study}

The study was limited to the presence or absence of infections without quantifying the parasite load, a situation that might not mean that students 
developed the disease. Entamoeba histolytica and E. dispar were not differentiated due to lack of the required reagents. In addition, a self-reported data collection method was used which may also be a source of potential bias.

\section{Ethical approval and consent to the participants}

Before collecting the data, the ethical review committee of Science College, Bahir Dar University cleared the study, and a letter describing the objective of the research was written to Bure town Administration Educational Office and the four Elementary Schools. Consent was obtained from the children's parents/guardians selected for the study after explaining the purpose and the procedures of the study. The study subjects who were positive for intestinal parasites were treated free of charge at the Health Center with drugs prescribed by a physician.

\section{RESULTS}

\section{Socio-demographic characteristics of the study participants}

All the 430 students selected for this study gave a stool sample for intestinal parasitic examination and filled the questionnaire about risk factors. One hundred ninety $(44.20 \%)$ students belonged to grades 1 to 4 and $240(55.80 \%)$ to grades 5 to 8 . The age of the participants ranged from 6 to 18 years; $47.4 \%$ were 6 to 11 years old and $52.6 \%$ were 12 to 18 years old (Table 1). More than half of the participants were urban dwellers $(66.5 \%)$; the number of male and female students was almost equal; $63 \%$ had literate father, while a little more than half $(54.7 \%)$ of them had illiterate mothers (no formal education); the fathers of some $65 \%$ of the students were engaged in farming and $71 \%$ of students had mothers who were housewives; and most were from a family size of 5 and above (69.1\%) (Table 1). Regarding hygienic, behavioral and environmental sanitation factors, $93.7 \%$ of the participants had latrine and $90 \%$ of them used the latrine for defecation. Some $74 \%$ of the participants used tap water for drinking. In contrast, $63 \%$ of the participants used to dump household waste in open fields, and a considerable proportion, i.e., $47.7 \%$, of the participants had a low level of knowledge about personal and food hygiene and about environmental sanitation (Table 2).

\section{Prevalence of intestinal parasitic infections}

The prevalence of infection was significantly higher in rural $(48 \%)$ than in urban (35\%) participants, and the difference was a statistically significant. Rate of intestinal parasitism was similar between the sexes. 
Table 1. Socio-demographic characteristics of school children attending at Bure town primary schools, Ethiopia, 2019. ( $\mathrm{N}=430)$.

\begin{tabular}{lll}
\hline Variables & Categories & Frequency (\%) \\
\hline Grade level & $1-4$ & $190(44.2)$ \\
Residence & $5-8$ & $240(55.8)$ \\
\multirow{2}{*}{ Age in year } & Urban & $286(66.5)$ \\
& Rural & $144(33.5)$ \\
Sex & $6-11$ & $204(47.4)$ \\
Mothers' educational status & $12-18$ & $226(52.6)$ \\
& Male & $212(49.3)$ \\
Mothers' occupation & Female & $218(50.7)$ \\
& Literate & $195(45.35)$ \\
Fathers' educational status & Illiterate & $235(54.65)$ \\
& Employee & $56(13)$ \\
Fathers' occupation & Merchant & $69(16)$ \\
& Housewife & $305(71)$ \\
& Literate & $271(63)$ \\
Family size & Illiterate & $159(37)$ \\
& Employee & $80(18.6)$ \\
& Merchant & $70(16.3)$ \\
& Farmer & $280(65.1)$ \\
& 3 and below & $32(7.44)$ \\
& 4 & $101(23.5)$ \\
\end{tabular}

The age group 12-18 years old (42\%) had higher overall infection rate than the age group 6-11 years (36\%), though not significant $(P>0.05)$. Intestinal parasitic infection was not significantly associated with educational status of mothers and fathers, with occupations of mothers and fathers and with family size $(P>0.05)$ (Table 2). Rate of IPI was significantly higher among participants who washed clothes at the river $(45.4 \%)$ than those who did it at home $(31.6 \%)$, and participants who had poor knowledge about personal and food hygiene, and environmental sanitation (48.3\%) than those who had good knowledge (31.1\%) $(P<0.05)$. The rest of the risk factors did not show significant association.

Some $40 \%(172 / 430)$ of the study participants were infected by at least one intestinal parasite. The prevalence of protozoan infection was 128(29.8\%), helminths was 51(11.9\%) and mixed infections was 10(2.3\%) (Table 3). Seven species of intestinal parasites (IPs) were detected, of which Entamoeba histolytica/dispar (22.1\%) was the most prevalent, followed by Giardia lamblia (8.6\%), Hookworms (6.8\%) and Ascaris lumbricoides (3.7\%). Hymenolepis nana, Trichuris trichuira and Taenia species were rare $(<1 \%$ prevalence). Some 
$162(37.7 \%)$ of the participants were found infected by single parasite, 9 $(2.09 \%)$ by two parasites and $1(0.23 \%)$ by three parasites (Table 3$)$.

Table 2. Prevalence of Intestinal Parasitic Infections (IPIs) among Bure primary school children by the different risk factors, Ethiopia, 2019.

\begin{tabular}{|c|c|c|c|c|}
\hline Variables & Categories & $\begin{array}{l}\text { Total } \\
\text { Number } \\
(\%)\end{array}$ & $\begin{array}{l}\text { Negative } \\
\text { No. }(\%)\end{array}$ & $\begin{array}{l}\text { Positive } \\
\text { No. }(\%)\end{array}$ \\
\hline \multirow[t]{2}{*}{ Residence $^{\mathrm{a}}$} & Urban & $286(66.5)$ & $186(65.0)$ & $100(35.0)$ \\
\hline & Rural & $144(33.5)$ & $75(52.1)$ & $69(47.9)$ \\
\hline \multirow[t]{2}{*}{ Age (year) } & $6-11$ & $204(47.4)$ & $130(63.7)$ & $74(36.3)$ \\
\hline & $12-18$ & $226(52.6)$ & $131(58.0)$ & $95(42.0)$ \\
\hline \multirow[t]{2}{*}{ Grade level } & $1-4$ & $190(44.2)$ & $121(63.7)$ & $69(36.3)$ \\
\hline & $5-8$ & $240(55.8)$ & $137(57.1)$ & $103(42.9)$ \\
\hline \multirow[t]{2}{*}{ Sex } & Male & $212(49.3)$ & $129(60.8)$ & $83(39.2)$ \\
\hline & Female & $218(50.7)$ & $131(60.1)$ & $86(39.9)$ \\
\hline \multirow[t]{3}{*}{ Mothers' education } & Literate & $195(45.4)$ & $117(60.0)$ & $78(40.0)$ \\
\hline & Illiterate & $232(54.0)$ & $144(62.1)$ & $88(37.9)$ \\
\hline & Other & 3 & 0 & 3 \\
\hline \multirow[t]{5}{*}{ Mothers' occupation } & $\begin{array}{l}\text { Government } \\
\text { employee }\end{array}$ & $30(7.0)$ & 16 & 14 \\
\hline & Merchant & $68(15.8)$ & $41(60.3)$ & $27(39.7)$ \\
\hline & Others & 5 & 2 & 3 \\
\hline & Private sector & 22 & 11 & 11 \\
\hline & Housewife & $305(70.9)$ & $191(62.6)$ & $114(37.4)$ \\
\hline \multirow[t]{2}{*}{ Fathers' education } & Literate & $271(63.0)$ & $162(59.8)$ & $109(40.2)$ \\
\hline & Illiterate & $159(37.0)$ & $99(62.3)$ & $60(37.7)$ \\
\hline \multirow[t]{4}{*}{ Fathers' occupation } & $\begin{array}{l}\text { Government } \\
\text { employee }\end{array}$ & $79(18.4)$ & $44(55.7)$ & $35(44.3)$ \\
\hline & Merchant & $70(16.3)$ & $44(62.9)$ & 26 \\
\hline & Others & $60(14.0)$ & $42(70.0)$ & 18 \\
\hline & Farmer & $221(51.4)$ & $130(58.8)$ & $91(41.2)$ \\
\hline \multirow[t]{4}{*}{ Family size } & 2 & 3 & 1 & 2 \\
\hline & 3 & 29 & 15 & 14 \\
\hline & 4 & $101(23.5)$ & $59(58.4)$ & $42(41.6)$ \\
\hline & 5 and above & 297(69.1) & $186(62.6)$ & $111(37.4)$ \\
\hline \multirow[t]{2}{*}{ Source of drinking water } & Tap water & $318(74.0)$ & $198(62.3)$ & $120(37.7)$ \\
\hline & $\begin{array}{l}\text { Unprotected } \\
\text { spring/stream }\end{array}$ & $112(26.1)$ & $63(56.3)$ & $49(43.8)$ \\
\hline \multirow{2}{*}{$\begin{array}{l}\text { Drinking water treatment } \\
\text { practice }\end{array}$} & Treated & $31(7.2)$ & $20(65.5)$ & $11(35.5)$ \\
\hline & Untreated & 399(92.8) & $238(59.6)$ & $161(40.4)$ \\
\hline \multirow{3}{*}{$\begin{array}{l}\text { Ways of disposing } \\
\text { household wastes }\end{array}$} & Burning & $133(30.9)$ & $91(68.4)$ & $42(31.6)$ \\
\hline & $\begin{array}{l}\text { Bury under } \\
\text { ground }\end{array}$ & 26 & 17 & 9 \\
\hline & On open field & $271(63.0)$ & $153(56.5)$ & $118(43.5)$ \\
\hline \multirow{2}{*}{$\begin{array}{l}\text { Hand washing habit before } \\
\text { a meal }\end{array}$} & Always & 383(89.1) & $236(61.6)$ & $147(38.4)$ \\
\hline & Sometimes & $47(10.9)$ & $25(53.2)$ & $22(46.8)$ \\
\hline
\end{tabular}


Ethiop. J. Sci. \& Technol. 13(2): 131-146, June 2020

\begin{tabular}{|c|c|c|c|c|}
\hline \multirow[t]{2}{*}{ Latrine availability } & Present & 403(93.7) & $243(60.3)$ & $160(39.7)$ \\
\hline & Absent & 27 & 18 & 9 \\
\hline \multirow{3}{*}{$\begin{array}{l}\text { Hand washing habit after } \\
\text { using toilet }\end{array}$} & Always & $196(45.6)$ & $121(61.7)$ & $75(38.3)$ \\
\hline & Sometimes & $194(45.1)$ & $122(62.9)$ & $72(37.1)$ \\
\hline & Not at all & $40(9.3)$ & $18(45.0)$ & $22(55.0)$ \\
\hline \multirow[t]{2}{*}{ Place of defecation } & Open field & $44(10.2)$ & $30(68.2)$ & $14(31.8)$ \\
\hline & Latrine & $386(89.8)$ & $231(59.8)$ & $155(40.2)$ \\
\hline \multirow{2}{*}{$\begin{array}{l}\text { Habit of eating uncooked } \\
\text { vegetables and unwashed } \\
\text { fruit }\end{array}$} & Yes & $375(66.0)$ & $227(60.5)$ & $148(39.5)$ \\
\hline & No & $55(34.0)$ & $34(61.8)$ & $21(38.2)$ \\
\hline \multirow{2}{*}{$\begin{array}{l}\text { Habit of eating } \\
\text { raw/uncooked meat }\end{array}$} & Yes & $306(71.2)$ & $178(58.2)$ & $128(41.8)$ \\
\hline & No & $124(28.8)$ & $83(66.9)$ & $41(33.1)$ \\
\hline \multirow{2}{*}{$\begin{array}{l}\text { Habit of swimming in } \\
\text { river }\end{array}$} & Yes & $219(50.9)$ & $135(61.6)$ & $84(38.4)$ \\
\hline & No & $211(49.1)$ & $126(59.7)$ & $85(41.3)$ \\
\hline \multirow[t]{2}{*}{ Practice of crossing river } & Yes & $333(77.4)$ & $205(61.6)$ & $128(38.4)$ \\
\hline & No & $97(22.6)$ & $56(57.7)$ & $41(42.3)$ \\
\hline \multirow[t]{2}{*}{ Bath } & Stream & $187(43.4)$ & $113(60.4)$ & $74(39.6)$ \\
\hline & At home & $243(56.5)$ & $148(60.9)$ & $95(39.1)$ \\
\hline \multirow[t]{2}{*}{ Washing clothes ${ }^{\mathrm{a}}$} & At home & $190(44.2)$ & $130(68.4)$ & $60(31.6)$ \\
\hline & At river & $240(55.8)$ & $131(54.6)$ & $109(45.4)$ \\
\hline \multirow{3}{*}{$\begin{array}{l}\text { Consistency of wearing } \\
\text { shoes }\end{array}$} & Always & $316(73.5)$ & $196(62.0)$ & $120(38.0)$ \\
\hline & Sometimes & $112(26.0)$ & $64(57.1)$ & $48(42.9)$ \\
\hline & Not at all & 2 & 1 & 1 \\
\hline \multirow[t]{2}{*}{ Dirty in fingernails } & Yes & $237(55.1)$ & $139(58.6)$ & $98(41.4)$ \\
\hline & No & $193(44.9)$ & $122(63.2)$ & $71(36.8)$ \\
\hline \multirow[t]{2}{*}{ KPFHES $^{\mathrm{a}, \mathrm{b}}$} & Good & $225(59.3)$ & $155(68.9)$ & $70(31.1)$ \\
\hline & Poor & $205(47.7)$ & $106(51.7)$ & $99(48.3)$ \\
\hline
\end{tabular}

${ }^{\mathrm{a}}=$ Significant at $\mathrm{P}$ value $\leq 0.05 ;{ }^{\mathrm{b}}=$ Knowledge about personal $\&$ food hygiene, and environmental sanitation.

\section{Logistic regression analysis of risk factors}

The most important risk factors for IPIs among Bure primary school children were identified using logistic regression analysis (Table 4). A bivariate analysis was first conducted with a 0.25 level of significance to select the candidate variables for multivariate analysis. Ten out of 25 variables were significant in the bivariate analysis (Table 4) and included in the multivariable analysis (Lemeshow et al., 2013). Of these risk factors, KPFHES (knowledge about personal and food hygiene, and environmental sanitation) and place of defecation were found to be predictors of IPIs (Table 4). 
Accordingly, the risk of being infected by IPIs was increased two times $(A O R=1.986, \quad C I=1.288-3.060, \quad P=0.002)$ in participants who had poor knowledge than those who had good knowledge about personal and food hygiene, and environmental sanitation. Regarding the place of defecation, participants who practiced open field defecation were $55.6 \%$ less likely to be infected by IPIs than those who used the latrine (Table 4).

Table 3. Prevalence of parasites detected on school children in primary schools at Bure town, north- west Ethiopia, 2019.

\begin{tabular}{llr}
\hline Parasite groups & Parasite species & Total number (\%) \\
\hline Protozoa & E. histolytica/dispar & $95(22.1)$ \\
& G. lamblia & $37(8.6)$ \\
Helminths & Hookworm & $29(6.7)$ \\
& A. lumbricoides & $16(3.7)$ \\
& Hymenolepis nana & $3(0.7)$ \\
& Trichuris trichuira & $2(0.5)$ \\
Single infection & Taenia species & $1(0.2)$ \\
Double infections & - & $162(37.7)$ \\
Multiple infections & - & $9(2.1)$ \\
Overall infections & - & 1 \\
& - & $172(40)$ \\
\hline
\end{tabular}

\section{DISCUSSION}

Developing countries continue to suffer from the persistent burden of IPIs (Kebede Derbie et al., 2012). Eradication efforts of these neglected diseases were largely unsuccessful due to multiple factors. Lack of information about local risk factors of IPIs from different localities is one constraint for effective intervention. The current study was, therefore, an effort to contribute for generating information about the occurrence of intestinal parasites in the study area. The overall prevalence of IPIs among primary school children in Bure town was high $(40 \%)$, corroborating previous reports on school children (3044\%) elsewhere in Ethiopia (Aschalew Gelaw et al., 2013; Alemneh Abera and Endalkachew Nibret, 2014; Admasu Haile et al., 2017; Megbaru Alemu et al., 2015). A number of other studies identified high risk communities, i.e., 55 to 81\% rate of IPIs (Abdi et al., 2015; Tilahun Alehegn et al., 2015; Tamirat Hailegebrael, 2017; Baye Sitotaw et al., 2019), who concluded that intestinal parasitosis continued to be a nationwide public health concern. In order to improve public health services and meet some of the Millennium Development Goals, the community-based accelerated expansion of health facilities in Ethiopia was launched and operated since 2004. With the current pace, however, it may be difficult for Ethiopia to achieve the 2020 strategic goals. 
Table 4. Bivariate and multivariate logistic regression analysis of potential risk factors associated with IPIs among school children at Bure primary schools, north-west Ethiopia, 2019.

\begin{tabular}{|c|c|c|c|c|c|}
\hline Variables & Categories & Total No. (\%) & Positive No. (\%) & COR (95\% C.I.) & AOR (95\% C.I.) \\
\hline \multirow[t]{2}{*}{ Grade level } & $1-4$ & $190(44.2)$ & $69(36.3)$ & $0.76(0.51-1.12)$ & - \\
\hline & $5-8$ & $240(55.8)$ & $103(42.9)$ & 1 & - \\
\hline \multirow[t]{2}{*}{ Residence } & Urban & $286(66.5)$ & $100(35.0)$ & 1 & - \\
\hline & Rural & $144(33.5)$ & $69(47.9)$ & $1.86(1.28-2.79)^{\mathrm{a}}$ & - \\
\hline \multirow[t]{2}{*}{ Age group } & $12-18$ & $226(52.6)$ & $95(42.0)$ & 1 & - \\
\hline & $6-11$ & $204(47.4)$ & $74(36.3)$ & $0.74(0.50-1.09)$ & - \\
\hline \multirow{3}{*}{$\begin{array}{l}\text { Hand washing habit after } \\
\text { toilet }\end{array}$} & Always & $196(45.6)$ & $75(38.3)$ & 1 & - \\
\hline & Sometimes & $194(45.1)$ & $75(38.7)$ & $1.02(0.67-1.52)$ & - \\
\hline & Not at all & $40(9.3)$ & $22(55.0)$ & $1.97(0.99-3.91)$ & - \\
\hline \multirow[t]{2}{*}{ Place of defecation } & Latrine & $386(89.8)$ & $158(40.9)$ & 1 & - \\
\hline & Open field & $44(10.2)$ & $14(31.8)$ & $0.67(0.35-1.31)$ & $0.42(0.20-0.89)^{\mathrm{a}}$ \\
\hline \multirow{2}{*}{ Place of washing clothes } & At home & $190(44.2)$ & $60(31.6)$ & 1 & - \\
\hline & At river & $240(55.8)$ & $109(45.4)$ & $1.90(1.27-2.82)^{\mathrm{a}}$ & - \\
\hline \multirow[t]{3}{*}{ Disposal of household wastes } & Burning & $133(30.9)$ & $42(31.6)$ & & - \\
\hline & Bury under ground & $26(6.0)$ & $9(34.6)$ & $1.15(0.47-2.8)$ & - \\
\hline & Open field & $271(63.0)$ & $121(44.6)$ & $1.75(1.13-2.7)^{\mathrm{a}}$ & - \\
\hline \multirow[t]{2}{*}{ Dirty finger nails } & No & $193(44.9)$ & $71(36.8)$ & 1 & - \\
\hline & Yes & $237(55.1)$ & $98(41.4)$ & $1.28(0.86-1.88)$ & - \\
\hline \multirow[t]{2}{*}{ KPFHES $^{\mathrm{b}}$} & Good & $225(59.3)$ & $70(31.1)$ & 1 & - \\
\hline & Poor & $205(47.7)$ & $99(48.3)$ & $1.95(1.31-2.87)^{\mathrm{a}}$ & $1.94(1.26-3)^{\mathrm{a}}$ \\
\hline \multirow{2}{*}{ Habit (eating uncooked meat) } & Yes & $306(71.2)$ & $128(41.8)$ & $1.52(0.97-2.34)$ & - \\
\hline & No & $124(28.8)$ & $41(33.1)$ & 1 & - \\
\hline
\end{tabular}

Note: $1=$ reference value; ${ }^{a}=$ statistically significant at $\mathrm{p} \leq 0.05, \mathrm{COR}=$ crude odds ratio; $\mathrm{AOR}=$ adjusted odds ratio; multivariate regression model for grade level, residence, age, place of defecation, hand washing habits after toilet use, uncooked meat eating habits, place of washing clothes, ways of disposing household wastes,dirty things in finger nails and knowledge about personal \& food hygiene and environmental sanitation for intestinal parasitic infections; ${ }^{k}$ nowledge about Personal \&Food hygiene, and Environmental Sanitation. 
Poverty related variables such as unsafe and inadequate water supply, unhygienic food consumption and overcrowded settlements are generally considered as the leading risk factors for intestinal parasitosis. However, Bure town is located in a moderate agro-ecological area and with surplus agricultural products. Therefore, the problem related to the prevalence of such diseases of poverty is likely due to a lack of awareness about the basics of prevention and control of parasitic diseases. Lack of knowledge could lead to a low level of personal hygiene and environmental sanitation.

Only a few studies in Ethiopia have shown relatively lower prevalence rates of IPIs (9.5 to 27\%) (Begna Tulu et al., 2014; Girum Tadesse, 2005; Aschalew Gelaw et al., 2013; Getaneh Alemu et al., 2015; Habtamu Woldesenbet et al., 2019). The reasons for such reduced prevalence may be that some of these studies were conducted after the mass de-worming program (Habtamu Woldesenbet et al., 2019) in the study population, or the study was conducted at the well-aware community such as university community schools in Gonder (Aschalew Gelaw et al., 2013). In addition, the technique used to identify intestinal parasites may influence the prevalence rate. For example, Girum Tadesse (2005) used only formal-ether concentration technique that might underestimate the result.

Out of the 25 variables considered in this study, a low level of awareness about personal and food hygiene and environmental sanitation were found to be the most important risk factor for IPIs among the study participants (Table 4). In line with this, Alum et al. (2010) emphasized that poor hygienic practices, primarily due to lack of proper handwashing habits, could significantly increase the rate of IPIs. Regarding the place of defecation, a contradicting result was observed where participants who practiced open field defecation were $55.6 \%$ less likely to be infected by IPIs than those who used latrine. Most of the participants $(89.8 \%)$ reported that they had latrines. Thus, it could likely be attributed to the quality of latrine, hygienic practices after latrine use and other factors for the infection.

Among the seven species of intestinal parasites (IPs) identified, Entamoeba histolytica/dispar was the predominant species (22.1\%). Similarly, Abddel-Aziz et al. (2010) in Central Sudan, Al-Harazi (2016) in Yemen, Tamrat Hailegebrael (2017) in Bahir Dar town, Ethiopia, have also reported that E. histolytica was the dominant parasite detected among school children. Indeed, this intestinal parasite is the most common in tropical areas where poor sanitation prevails. In a number of other studies, however, A. lumbricoides, Giardia lamblia or Hookworm species were found to be the most dominant species frequently identified among school children (Megbaru Alemu et al., 2015; Tilahun Alehegn et al., 2015; Admasu Haile et al., 2017; Baye Sitotaw et al., 2019; 
Getaneh Alemu et al., 2019; Habtamu Woldesenbet et al., 2019). Giardia lamblia (8.6\%), Hookworms (6.75\%) and Ascaris lumbricoides (3.7\%) were also detected among the participants of this study, though they were at a lower rate compared to other similar studies (Alemneh Abera and Endalkachew Nibret, 2014; Ashenafi Abosie and Mohammed Seid, 2014; Mulusew Andualem, 2014; Tamirat Hailegebrael, 2017; Getaneh Alemu et al., 2018; Baye Sitotaw et al., 2019). The rate of multiple infections was relatively low in this study $(10,2.3 \%)$ unlike the results in many other studies (e.g., Mulusew Andualem, 2014)

\section{CONCLUSION}

In this study, we have confirmed that a significant proportion of school children in Bure town were infected with intestinal parasites (IPs). This indicates that IPIs are important public health concerns in the area, and calls for immediate action to alleviate the problem. We have also confirmed that the same range (and prevalence) of intestinal parasitic species occur as previous reports in other places in Ethiopia and elsewhere in the globe (particularly in developing countries). Of the potential risk factors considered, knowledge (about personal and food hygiene, and environmental sanitation) and place of defecation were found to be the most important risk factors for IPIs among the students in Bure primary schools. Bure town health service quality and awareness creation activities on the prevailing risk factors should thus be properly evaluated. All concerned bodies (decision-makers, mass media, health workers, religious leaders, and teachers) should work in collaboration to reduce the parasite burden. Practical action plans for effective prevention and control of IPIs in the study area should be in place. Primarily, an awareness creation campaign should be conducted on school children and their parents. In addition, coverage and frequency of the de-worming campaign should be improved to eliminate soiltransmitted helminths in the study area.

\section{ACKNOWLEDGEMENTS}

We would like to thank health workers at Bure Health Center as well as participating students and the school community involved in the study. This research was funded by Bahir Dar University and the Ministry of Education, Ethiopia. 


\section{REFERENCES}

Abdel-Aziz, M.A., Afifi, A.A., Malik, E.M and Adam, I. (2010). Intestinal protozoa and intestinal helminthic infections among schoolchildren in Central Sudan. Asian Pacific Journal of Tropical Medicine 3(4): 292-293.

Admasu Haile, Temesgen Abera and Daniel Dana (2017). The prevalence of intestinal parasitic infection and associated factors among primary school children in Gurage Zone, South Ethiopia. Journal of Pharmacy and Alternative Medicine 15:8-15

Alemneh Abera and Endalkachew Nibret (2014). Prevalence of gastrointestinal helminths infection and associated risk factors among school children in Tilili town, north-west Ethiopia. Asian Pacific Journal of Tropical Disease 2(14):525-530.

Alganesh Gebreyohanns, Melese Hailu Legese, Mistire Wolde, Gemechu Leta and Geremew Tasew (2018). Prevalence of intestinal parasites versus knowledge, attitude and practices (KAPs) with special emphasis to Schistosoma mansoni among individuals who have river water contact in Addiremets town, Western Tigray, Ethiopia. PloS One 13(9):e0204259.

AL-Harazi, T. (2016). Prevalence and Risk Factors associated with intestinal parasitic infection among patients in Taiz City, Yemen. British Microbiology Research Journal International 16(3): 1-7.

Alum, A., Rubino, J.R and Ijaz, M.K. (2010). The global war against intestinal parasites - should we use a holistic approach? International Journal of Infectious Diseases 14(9): e732-8.

Aschalew Gelaw, Belay Anagaw, Bethel Nigussie, Betrearon Silesh, Atnad Yirga, Meseret Alem, Mengistu Endris and Baye Gelaw (2013). Prevalence of intestinal parasitic infections and risk factors among schoolchildren at the University of Gondar Community School, north-west Ethiopia: a cross-sectional study. BMC Public Health 13(1): 304.

Ashenafi Abossie and Mohammed Seid (2014). Assessments of the prevalence of intestinal parasitic infection and associated risk factors among primary school children in Chencha town, southern Ethiopia. BMC Public Health 14(166): 47-58.

Baye Sitotaw, Haileeyesus Mekuriaw and Destaw Damtie (2019). Prevalence of intestinal parasitic infections and associated risk factors among Jawi primary school children, Jawi town, north-west Ethiopia. BMC Infectious Diseases 19(1):341.

Begna Tulu, Solomon Taye and Eden Amsalu (2014). Prevalence and its associated risk factors of intestinal parasitic infections among Yadot primary school children of south-eastern Ethiopia: a cross-sectional study. BMC Research Notes 7(1): 848.

Collier, P. (2007). Why the poorest countries are failing and what can be done about it. Wider Angle 2: 1-3.

Getaneh Alemu, Zeleke Aschalew and Eshetu Zerihun (2018). Burden of intestinal helminths and associated factors three years after initiation of mass drug administration in the Arbaminch Zuria district, southern Ethiopia. BMC Infectious Diseases 18(1): 435.

Girum Tadesse (2005). The prevalence of intestinal helminthic infections and associated risk factors among school children in Babile town, eastern Ethiopia. Ethiopian Journal of Health Development 19(2) 140-147. 
Habtamu Weldesenbet, Abdulsemed Worku and Teha Shumbej (2019). Prevalence, infection intensity and associated factors of soil transmitted helminths among primary school children in Gurage zone, South Central Ethiopia: a cross-sectional study design. BMC Research Notes 12(1): 231.

Hotez, P.J., Fenwick, A., Savioli, L and Molyneux, D.H. (2009). Rescuing the bottom billion through control of neglected tropical diseases. Lancet 373(9674): 1570-1575.

Hotez, P.J., Alvarado, M., Basáñez, M.G., Bolliger, I., Bourne, R., Boussinesq, M., Brooker, S.J., Brown, A.S., Buckle, G., Budke, C.M and Carabin, H. (2014). The global burden of disease study 2010: interpretation and implications for the neglected tropical diseases. PLoS Neglected Tropical Diseases 8(7): p. e2865.

Kebede Deribe, Kadu Meribo, Teshome Gebre, Asrat Hailu, Ahmed Ali, Abraham Asefa and Gail Davey (2012). The burden of neglected tropical diseases in Ethiopia, and opportunities for integrated control and elimination. Parasites and Vectors 5(1): 240.

Hosmer Jr,D.W., Lemeshow, S. and Sturdivant R.X. (2013). Applied logistic regression. John Wiley \& Sons, Inc., New Jersey.

Mascarini-Serra, L. (2011). Prevention of soil-transmitted helminth infection. Journal of Global Infectious Diseases 3(2): 175-82.

Megbaru Alemu, Habtamu Bedemo, Gessessew Bugssa, Sena Bayissa and Kiros Tedla (2015). Epidemiology of intestinal parasite infections among Kindergarten Children in Mekelle Town, Northern Ethiopia. International Journal of Pharma Sciences and Research 6(11): 1391-1395.

Merem Abdi, Endalkachew Nibret and Abaiyneh Munshe (2015). Prevalence of intestinal helminthic infections and malnutrition among school Children of the Zegie Peninsula, northwestern Ethiopia. Journal of Infection and Public Health 10(1): 8492.

Mulusew Andualem (2014). Parasitic infection and associated factors among the primary school Children in Motta Town, Western Amhara, Ethiopia. American Journal of Public Health Research 2(6): 248-254.

Naing, L., Winn, T and Rusil, B.N. (2006). Practical issues in calculating sample size for prevalence studies. Archives of Orofacial Sciences 1:9-14.

Ojha, S.C., Jaide, C., Jinawath, N., Rotjanapan, P and Baral, P. (2014). Geohelminths: public health significance. The Journal of Infection in Developing Countries 8(1):516

Palmeirim, M.S., Ouattara, M., Esse, C., Koffi, V.A., Assare, R.K., Hurlimann, E., Coulibaly, J.T., Diakite, N.R., Dongo, K., Bonfoh, B and Utzinger, J. (2018). Are school children less infected if they have good knowledge about parasitic worms? A case study from rural Côte d'Ivoire. BMC Public Health 18(1):951.

Sackev, M.E. (2001). Intestinal factors and parasite infections: prevalence, risk factors and consequences for child growth, Iron status and development in rural Ecuador. MSc. Thesis, Virginia Polytechnic and State University, Ecuador.

Sady, H., Al-Mekhlafi, H.M., Atroosh, W.M., Al-Delaimy, A.K., Nasr, N.A., Dawaki, S., Al-Areeqi, M.A., Ithoi, I., Abdulsalam, A.M., Chua, K.H and Surin, J. (2015). Knowledge, attitude, and practices towards schistosomiasis among rural population in Yemen. Parasites and Vectors 8(1):436.

Tamirat Hailegebriel (2017). Prevalence of Intestinal Parasitic infection and associated risk factors among students at Dona Berber Primary school, Bahir Dar Ethiopia. BMC Infectious Diseases 17(362):1-8. 
Tilahun Alelign, Abraham Degarege and Berhanu Erko (2015). Prevalence and factors associated with under-nutrition and anaemia among school children in Durbete Town, north-west Ethiopia. Archives of Public Health 73(1): 34-38.

WHO (World Health Organization) (2000). Basic laboratory method in Medical Parasitology, Geneva, Switzerland. Pp. 39-61.

WHO (World Health Organization) (2010). Working to overcome the global impact of neglected tropical diseases: first WHO report on neglected tropical diseases (No. WHO/HTM/NTD/2010.1), Geneva, Switzerland.

Williams, K., Thomson, D., Seto, I., Contopoulos-Ioannidis, D.G., Ioannidis, J.P., Curtis, S., Constantin, E., Batmanabane, G., Hartling, L and Klassen, T. (2012). Standard 6: age groups for pediatric trials. Pediatrics 129(3): 153-160. 